\title{
Co2 LaSer Powered Metal 3D Printer PARAMETER Influence ON PART QUALity
}

\author{
Arturs Vevers, Artis Kromanis \& Eriks Gerins
}
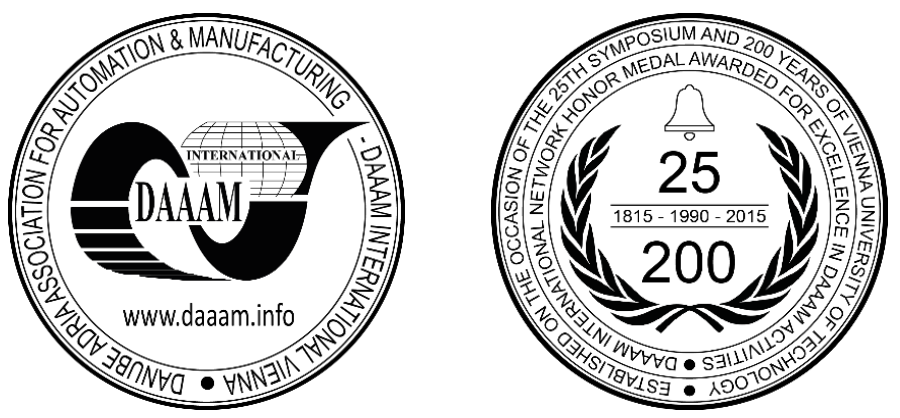

This Publication has to be referred as: Vevers, A[rturs]; Kromanis, A[rtis] \& Gerins, E[riks] (2018). Co2 Laser Powered Metal 3D Printer Parameter Influence on Part Quality, Proceedings of the 29th DAAAM International Symposium, pp.0955-0960, B. Katalinic (Ed.), Published by DAAAM International, ISBN 978-3-902734-20-4, ISSN 1726-9679, Vienna, Austria

DOI: $10.2507 / 29$ th.daaam.proceedings.137

\begin{abstract}
Paper presents experiments with processing parameters on additive manufacturing machine working with SLM method for stainless steel 316L. Most of the experiments which have been done before are on machines which are equipped with fiber optics lasers and these processing parameters cannot be used on machines which are equipped with $\mathrm{CO} 2$ lasers. Aim of research was to test processing parameter influence on printed material density and mechanical properties. Experiments were performed on Aurora Labs Titanium Pro machine which is equipped with two CO2 lasers with total power of $300 \mathrm{~W}$. For processing parameters laser power was used at $300 \mathrm{~W}$, laser travel speed was varied from $1500 \mathrm{~mm} / \mathrm{min}$ to $2400 \mathrm{~mm} / \mathrm{min}$. Hatch distance was changed from 0.8 to $0.3 \mathrm{~mm}$ and layer thickness was changed from $30 \mu \mathrm{m}$ to $50 \mu \mathrm{m}$. Specimens were polished and material density was evaluated by imaging analysis software and tests on tensile strength were performed.
\end{abstract}

Keywords: additive manufacturing; selective laser melting; stainless steel 316L; CO2 laser

\section{Introduction}

In the recent years metal additive manufacturing also known as metal 3D printing has been evolving with huge steps. There are many companies which produce metal 3D printers and this technology becomes even more available for production. In metal additive manufacturing there are various production methods but from all of them selective laser melting (SLM) is the most popular because most of the metal 3D printer manufacturers use this method.[1] The biggest disadvantage of SLM is high 3D printer price due to expensive laser and other components. There are some 3D printer manufacturers which have tried to find different approach and started to develop other production methods but there are also some manufacturers which have tried to use less expensive components to achieve good results. The problem is that it is not possible to use the same processing parameters for the same material on all types of machines. At the moment most of the experiments and most of the researches have been made with samples which have been produced on machines which are equipped with fiber optic lasers.[2] These processing parameters cannot be used on machines which are equipped with $\mathrm{CO} 2$ lasers. The aim of this research is to investigate influence of processing parameters on the material density and mechanical properties of SLM parts produced on metal 3D printer which is equipped with $\mathrm{CO} 2$ laser. 
An auxiliary goal is to find processing parameters which can maintain material density higher than $95 \%$. These parameters may be used for further research where new materials and its combinations may be developed otherwise impossible through traditional manufacturing or metallurgy methods.

\section{Materials and methods}

For this research experiments have been performed using stainless steel 316L material grade. This material grade is widely used in additive manufacturing industry because it has good mechanical properties and it is one of the least expensive materials.[3] SS316L powder has been produced by Höganäs AB, this powder is with average grain size from $20-50 \mu \mathrm{m}$. Experiments have been performed on Aurora Labs Titanium Pro S1 metal 3D printer. Aurora Labs Titanium Pro machine is equipped with two $150 \mathrm{~W} \mathrm{CO} 2$ lasers with total power of $300 \mathrm{~W}$. Wavelength of laser beam is $10600 \mathrm{~nm}$. Build envelope size for this machine is 200x200x500 mm.[4]

Decision was made to produce cube specimens with size 10x10x10 mm. Each cube has been printed using different parameters as shown in table 1 to 3 and after printing process each cube was polished and checked with microscope to examine material density. The following processing parameters were used - laser power for all experiments has been set to maximum power of $300 \mathrm{~W}$, hatch spacing has been varied from 0.3 to $0.8 \mathrm{~mm}$, laser travel speed has been changed from $1500 \mathrm{~mm} / \mathrm{min}$ to $2400 \mathrm{~mm} / \mathrm{min}$. The first set of experiments has been performed with $50 \mu \mathrm{m}$ layer thickness with 10 different processing parameter combinations. Based on the results with $50 \mu$ m layer thickness following experiments where performed with $40 \mu \mathrm{m}$ layer thickness and $30 \mu \mathrm{m}$ layer thickness in the same time processing parameters where changed to achieve higher density printed material. After cube specimen production the samples were polished on Struers microstructure polishing machine and surfaces were prepared with surface etching using nitric acid (HNO3). Porosity level was detected using microscope and imaging analysis software ImageJ.

\section{Laser power measurements}

The Aurora Labs Titanium Pro uses six mirror system to steer the laser beam from two $150 \mathrm{~W}$ CO2 lasers to build chamber and focus in one point. To determine how much power is left when beam reaches powder laser power measuring was done using laser power meter. Laser power measuring was done according to Mahoney Laser Power meter measuring instructions.[5] Mahoney CO2 laser power meter has thermal sensor with diameter $30 \mathrm{~mm}$ which has to be placed in laser beam. It is calibrated to measure laser power for $9 \mathrm{sec}$. Sensor was installed on machine and laser was switched on exactly for $9 \mathrm{sec}$. Sensor has to be cooled down to room temperature and scale adjusted to zero before the next measurement. In the beginning a power was measured for both lasers separately and each laser at max power reached $120 \mathrm{~W}$. After checking each laser separately laser power was measured at build plate where both lasers are focused in one point. Laser power reached $160 \mathrm{~W}$ from both lasers which means that there are around $35 \%$ power loses in mirror system. Both lasers indicated some loss of power because this printer has been used for more than 7000 hours already.

$\mathrm{CO} 2$ laser have longer wavelength compared to fiber lasers which means that to get the same energy density it is necessary to use more powerful CO2 laser than fiber laser. Aurora Labs Titanium Pro printer when focusing both lasers in one point with focal length $100 \mathrm{~mm}$ have around $0.5 \mathrm{~mm}$ focal point diameter which means that focal point area is $0.2 \mathrm{~mm}^{\wedge} 2$. With previously measured $160 \mathrm{~W}$ power it gives energy density of $800 \mathrm{~W} / \mathrm{mm}^{\wedge} 2$.

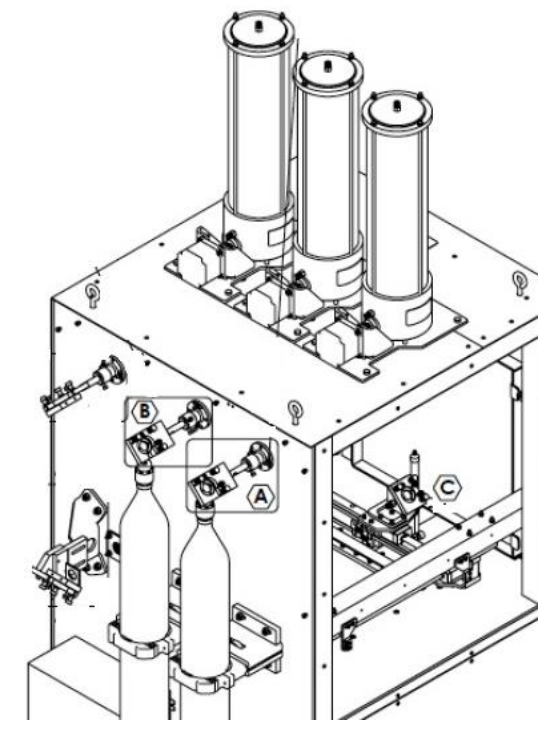

Fig. 1. Laser power measuring points - a) and b) separately for each laser and point c) for both lasers focused in one point 


\section{Material density results}

Research was performed with many processing parameter combinations as shown in tables 1 to 3. Purpose of this experiment was to find processing parameters which would allow to print parts of SS316L with material density higher than $95 \%$ because experiments with machines which are equipped with fiber optics laser have showed results reaching even higher density than $98 \%$.[6][7]

First experiments were performed with Aurora Labs suggested processing parameters and then processing parameters were varied to increase and decrease energy density in order to find the most effective values of processing parameters. Parameters were changed to see which parameter gives biggest influence on material density. Results of 50 $\mu \mathrm{m}$ layer thickness specimens indicated that this layer thickness is too thick for $300 \mathrm{~W} \mathrm{CO} 2$ laser. All ten specimens with $50 \mu \mathrm{m}$ layer thickness were with very high level of porosity. The best result reached density of $80 \%$ with processing parameters of $0.3 \mathrm{~mm}$ hatch spacing and laser travel speed $33 \mathrm{~mm} / \mathrm{s}$. The following sample was printed with highest energy density. Achieved results indicated that decreasing laser travel speed or decreasing hatch distance improved material density which means that for SS316L material grade with $\mathrm{CO} 2$ laser the energy density has to be higher than maximum which was used in this experiment.

To increase energy density one option would be to decrease laser travel speed even lower than $15 \mathrm{~mm} / \mathrm{s}$ and leave hatch spacing under $0.4 \mathrm{~mm}$ or repeat similar experiment with lower layer thickness. Decision was made to produce next batch with $40 \mu \mathrm{m}$ layer thickness. Decreasing layer thickness by $10 \mu \mathrm{m}$ would increase energy density by $25 \%$ with the same parameters for hatch spacing and laser travel speed.

Batch with $40 \mu \mathrm{m}$ layer thickness represented higher material density. As it was predicted, a sample with highest energy density indicated also the highest material density. The best result by imaging analysis software was $97 \%$ density. Results indicated that very important is hatch spacing and samples with $40 \mu \mathrm{m}$ and $50 \mu \mathrm{m}$ layer thickness indicated best results with $0.3 \mathrm{~mm}$ hatch spacing.

The final experiment batch was produced with $30 \mu \mathrm{m}$ layer thickness. This time the samples were printed only with $0.3 \mathrm{~mm}$ hatch spacing and with three different laser travel speeds. Very good material density was observed. With laser travel speed set to $25 \mathrm{~mm} / \mathrm{s}$, density was higher than $95 \%$.

\begin{tabular}{|l|c|c|c|c|c|c|c|c|c|c|}
\hline Sample No. & 1 & 2 & 3 & 4 & 5 & 6 & 7 & 8 & 9 & 10 \\
\hline Layer thickness $(\mathrm{mm})$ & 0,05 & 0,05 & 0,05 & 0,05 & 0,05 & 0,05 & 0,05 & 0,05 & 0,05 & 0,05 \\
\hline Laser power $(\mathrm{W})$ & 160 & 160 & 160 & 160 & 160 & 160 & 160 & 160 & 160 & 160 \\
\hline Hatch spacing $(\mathrm{mm})$ & 0,6 & 0,6 & 0,6 & 0,6 & 0,6 & 0,6 & 0,6 & 0,5 & 0,4 & 0,3 \\
\hline Laser travel speed $(\mathrm{mm} / \mathrm{s})$ & 33 & 30 & 25 & 37 & 40 & 43 & 47 & 33 & 33 & 33 \\
\hline Energy density $\left(\mathrm{J} / \mathrm{mm}^{\wedge}\right)$ & 160 & 177,8 & 213,3 & 145,5 & 133,3 & 123,1 & 114,3 & 192 & 240 & 320 \\
\hline Calculated density $(\%)$ & 70 & 70 & 74 & 70 & 68 & 66 & 65 & 71 & 75 & 80 \\
\hline
\end{tabular}

Table 1. Processing parameters with $50 \mu \mathrm{m}$ layer thickness.

\begin{tabular}{|l|c|c|c|c|c|c|c|c|c|c|}
\hline Sample No. & 11 & 12 & 13 & 14 & 15 & 16 & 17 & 18 & 19 & 20 \\
\hline Layer thickness (mm) & 0,04 & 0,04 & 0,04 & 0,04 & 0,04 & 0,04 & 0,04 & 0,04 & 0,04 & 0,04 \\
\hline Laser power $(\mathrm{W})$ & 160 & 160 & 160 & 160 & 160 & 160 & 160 & 160 & 160 & 160 \\
\hline Hatch spacing (mm) & 0,3 & 0,3 & 0,3 & 0,3 & 0,4 & 0,4 & 0,4 & 0,5 & 0,5 & 0,5 \\
\hline Laser travel speed (mm/s) & 25 & 30 & 33 & 40 & 25 & 30 & 40 & 25 & 30 & 40 \\
\hline Energy density & 533,3 & 444,4 & 404 & 333,3 & 400 & 333,3 & 250 & 320 & 266,7 & 200 \\
\hline Calculated density (\%) & 93 & 92 & 91 & 90 & 91 & 91 & 89 & 90 & 85 & 78 \\
\hline
\end{tabular}

Table 2. Processing parameters with $40 \mu$ m layer thickness.

\begin{tabular}{|l|c|c|c|}
\hline Sample No. & 21 & 22 & 23 \\
\hline Layer thickness $(\mathrm{mm})$ & 0,03 & 0,03 & 0,03 \\
\hline Laser power $(\mathrm{W})$ & 160 & 160 & 160 \\
\hline Hatch spacing $(\mathrm{mm})$ & 0,3 & 0,3 & 0,3 \\
\hline Laser travel speed $(\mathrm{mm} / \mathrm{s})$ & 25 & 30 & 33 \\
\hline Energy density $\left(\mathrm{J} / \mathrm{mm}^{\wedge} 2\right)$ & 711,1 & 592,6 & 538,7 \\
\hline Calculated density $(\%)$ & 97 & 96 & 94 \\
\hline
\end{tabular}

Table 3. Processing parameters with $30 \mu \mathrm{m}$ layer thickness. 

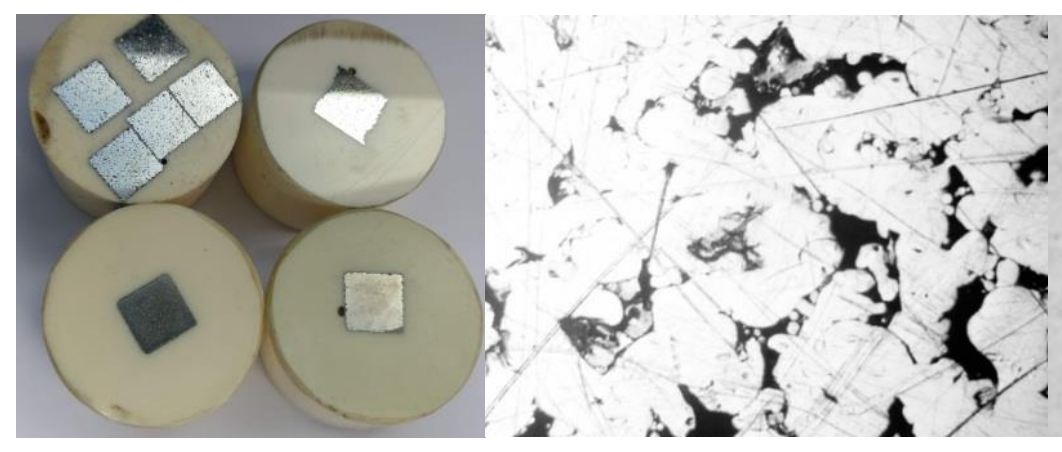

Fig. 2. a) Cube specimens after polishing; b) Material density for sample No. 8; and c) Material density for sample No.

21.

\section{Tensile strength results}

The main purpose of this research was to find processing parameters which can maintain material density higher than $95 \%$. At this density mechanical properties of material should be close to level which 316L grade should maintain by ISO standard. Experiment results obtained by the machines which are equipped with fiber optics lasers shows that SLM technology can achieve better results than standard requires.[8][9][10]

Tensile strength test was based on the same parameters which were used to produce cube specimens for material density investigation. Decision was made to produce tensile strength samples with using three types of processing parameters. One sample was produced with processing parameters of No. 19, the next sample was produced with processing parameters of No. 23 and the last one with processing parameters which reached the highest density level the processing parameter setup No. 21. The following test represented how processing parameters affect not only material density but also material mechanical properties.

Tensile strength test specimen was produced with following parameters - layer thickness $50 \mu \mathrm{m}$, laser travel speed was set to $2000 \mathrm{~mm} / \mathrm{min}$, hatch distance was $0.6 \mathrm{~mm}$ and laser power was set to maximum $300 \mathrm{~W}$ in printer's software but as measured before in reality the power, which reach the metal powder, is $160 \mathrm{~W}$. Sample was produced on supports with $10 \mathrm{deg}$. inclination relative to a horizontal plane. See Fig. 3. This positioning on the plate was chosen to avoid curl effect and help to minimize distortion during printing process. This is suggested in German standard for additive manufacturing VDI 3405.[11]
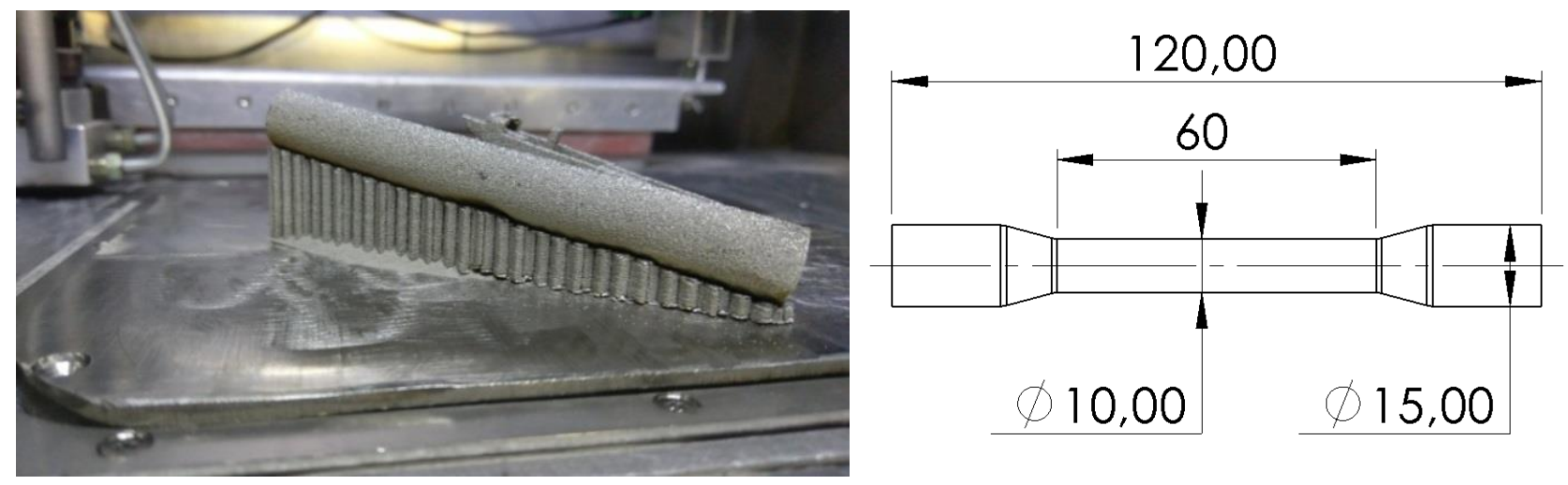

Fig. 3. Tensile strength sample after printing and dimensions for machining

To maintain precise diameter for tensile strength tests the sample was machined according to standard dimensions. Overall length $120 \mathrm{~mm}$, diameter $10 \mathrm{~mm}$ and testing zone $60 \mathrm{~mm}$. Machined sample was tested in Hegewald \& Peschke Inspekt 250 tensile strength machine and as it was expected after visual inspection it resulted in very bad results.

Maximum tensile strength value was $147 \mathrm{MPa}$ which is more than 3 times less than standard and elongation was only $8 \%$. For SS316L grade tensile strength value should be at least $485 \mathrm{MPa}$ and elongation should be at least $40 \%$. During tensile strength testing it was possible to see that sample started to crack very early due to high porosity level. 


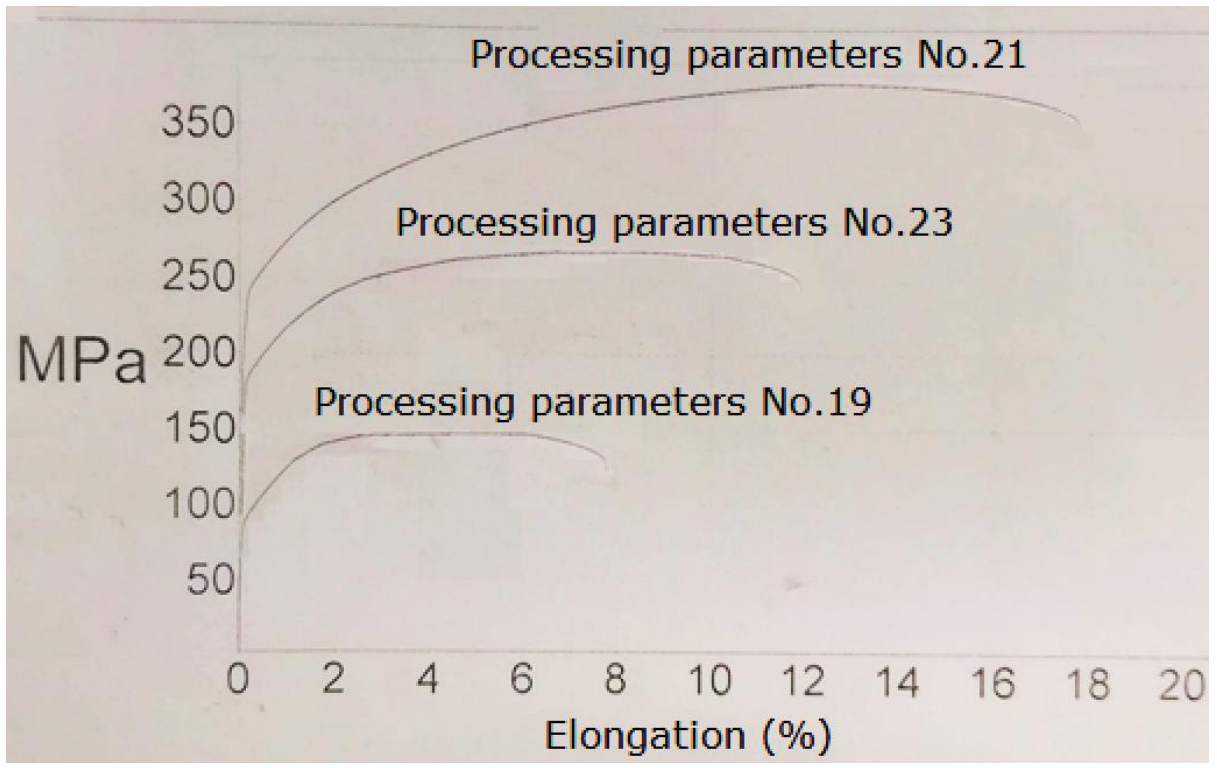

Fig. 4. Tensile strength graphic for samples Nos. 19, 21 and 23

Next tensile strength sample was produced with following processing parameters - layer thickness $30 \mu \mathrm{m}$, laser travel speed was set to $2000 \mathrm{~mm} / \mathrm{min}$, hatch distance was $0.3 \mathrm{~mm}$. This sample reached tensile strength value $260 \mathrm{MPa}$ and elongation $12 \%$.

Tensile strength test sample which achieved the best results was produced with following processing parameters layer thickness $30 \mu \mathrm{m}$, laser travel speed was set to $1500 \mathrm{~mm} / \mathrm{min}$, hatch distance was $0.3 \mathrm{~mm}$. This sample reached tensile strength value $380 \mathrm{MPa}$ and elongation $18 \%$.

The following experiments approved density test results and their relationship with tensile strength. The parameters which maintained higher material density achieved higher tensile strength test results. The following experiments were successful, but it would be necessary to continue further experiments with new $\mathrm{CO} 2$ lasers which can maintain at least $200 \mathrm{~W}$ power at surface of built plate.

\section{Conclusion}

It was essential to collect as much data as possible with many processing parameter combinations to prove abilities of 3D printing for real world manufacturing requirements. Many samples were unsuccessful from the view of material density, but the data will be useful for further experiments in developing new materials using 3D printing capabilities. Main goal of experiment was achieved and it was possible to reach predetermined target and find processing parameters which can maintain material density higher than $95 \%$. Experiment data can be used on similar SLM machines which are equipped with $\mathrm{CO} 2$ lasers and the processing parameters which reached the best results can be used as base parameters for next experiments with SS316L material or similar materials. The results of experiment and achieved goal allow to proceed on further experiments with materials including additives to develop new materials suitable for $3 \mathrm{D}$ printing.

Experiments were performed on less expensive metal 3D printer and results indicated that it is capable to produce good quality parts. There would be necessary to make some upgrades to reach higher quality and achieve results closer to machines which are equipped with fiber optics lasers. If we consider that this metal 3D printer which was used for experiments has worked for around 8000 hours already, then further research would be necessary to investigate if machine with new more powerful $\mathrm{CO} 2$ lasers and smaller laser focus distance can achieve higher results for tensile strength and material density with the same laser travel speed, layer thickness and hatch distance.

\section{References}

[1] Ian Gibson, D. Rosen, and Brent Stucker, (2013). “Additive Manufacturing Technologies,” Rapid Manuf. Assoc., pp. 10-12.

[2] P. Hanzl, M. Zetek, T. Bakša, and T. Kroupa, (2015). "The influence of processing parameters on the mechanical properties of SLM parts,” Procedia Eng., vol. 100, no. January, pp. 1405-1413.

[3] I. Zetkova, L. Kucerova, M. Zetek, J. Cesanek, P. Hanzl, and M. Dana, (2017).“Evaluation of Metal Powder for Additive Manufacturing of Margaring Steel," pp. 0410-0416.

[4] A. L. Ltd, (2017) “Aurora Labs S-Titanium Pro Installation Manual,” no. V1.2, p. 25.

[5] M. Ltd, (2017). "Mahoney Co2 laser power meter user manual," pp. 1-9. 
[6] C. Kamath, B. El-Dasher, G. F. Gallegos, W. E. King, and A. Sisto, (2014)."Density of additively-manufactured, 316L SS parts using laser powder-bed fusion at powers up to $400 \mathrm{~W}$,” Int. J. Adv. Manuf. Technol., vol. 74, no. 14, pp. 65-78.

[7] A. Ilie, H. Ali, and K. Mumtaz,(2017). "In-Built Customised Mechanical Failure of 316L Components Fabricated Using Selective Laser Melting," Technologies, vol. 5, no. 1, p. 9.

[8] J. Delgado, J. Ciurana, and C. A. Rodríguez, (2012). "Influence of process parameters on part quality and mechanical properties for DMLS and SLM with iron-based materials," Int. J. Adv. Manuf. Technol., vol. 60, no. 5-8, pp. 601-610.

[9] V. Ben, (2011). "Study of the Optimized Parameters of Stainless Steel 316L Powder for Rapid Prototyping Based on Selective Laser Melting Technique Apinya Laohaprapanon A Thesis Submitted in Fulfillment of the Requirements for the Degree of Master of Engineering in Materia," Rapid Prototyp. J., vol. 13, no. 4, pp. $196-203$.

[10] J. Sedlak, D. Rican, M. Piska, and L. Rozkosny, (2015). "Study of materials produced by powder metallurgy using classical and modern additive laser technology," Procedia Eng., vol. 100, no. January, pp. 1232-1241.

[11] VDI, (2015). Additive manufacturing processes, rapid manufacturing Design rules for part production using laser sintering and laser beam melting. 